\title{
"CAMINHAR PELOS PRÓPRIOS CAMINHOS": A PERSISTÊNCIA DOS INDÍGENAS DA SERRA NEVADA DE SANTA MARTA (COLÔMBIA) NOS CAMINHOS DA "CULTURA PRÓPRIA"
}

PATRÍCIA LORA LÉON ${ }^{1}$

UNICAMP

\begin{abstract}
RESUMO: O objetivo deste artigo é descrever "os caminhos próprios" do pensamento de quatro povos indígenas da Colômbia (Kogi, Wiwa, Arhuaco e Kankuamo) através das narrativas que apelam aos princípios e dispositivos a partir dos quais opera a cultura própria. Discuto o sentido que a cultura própria detém para "a comunicação essencial" indígena com a diversidade física e espiritual do universo. Aponto como desde o sentido da comunicação imbuído em Yuluka - princípio que atravessa e acompanha o sentido de ser e do agir indígena articulam-se outros elementos fundamentais para o pensamento e a cultura própria (Alúna e Sewá), os quais possibilitam ao homem cumprir a sua missão originária do cuidado e da ligação permanente entre tudo quanto existe no mundo.
\end{abstract}

PALAVRAS-CHAVE: Pensamento ameríndio; filosofia política; cosmopolítica; povos indígenas (Colômbia).

ABSTRACT: This paper aims to describe the "own ways" of thought of four indigenous people from Colombia (Kogi, Wiwa, Arhuaco and Kankuamo). The research focuses on the fundamental narratives that invoke principles and dispositifs considered essential for its own culture. I discuss the meaning of own culture to the indigenous' "essential communication" and their relationship with the physical and spiritual diversity of the universe. From the sense of communication expressed in Yuluka - the principle that accompanies the native sense of being and acting -, I present how other key principles are articulated to thought and own culture functioning (Alúna and Sewá). I analyze these principles, especially the assessment that indicates they enable mankind to fulfill his original mission of care and constant communication between all that exists in the world.

KEYWORDS: Amerindian thought; political philosophy; cosmopolitics; indigenous people (Colombia).

\footnotetext{
${ }^{1}$ Possui graduação em Comunicação Social - Jornalismo pela Universidade Central de Bogotá (Colômbia) e mestrado em Pesquisa Social Interdisciplinária pela Universidade Distrital de Bogotá (Colômbia). Atualmente é doutoranda no Programa de Pós Graduação em Ciências Sociais da Unicamp. Tem experiência em pesquisa social interdisciplinária com ênfase em comunicação, jornalismo, direitos humanos, cultura política, filosofia política e ética aplicada, atuando recentemente nos seguintes temas: etnologia indígena, filosofia política, pensamento ameríndio, cosmopolítica e descolonização epistêmica. E-mail: patoloraleon@gmail.com.
}

Espaço Ameríndio, Porto Alegre, v. 7, n. 1, p. 170-195, jan./jun. 2013. 
PATRÍCIA LORA LÉON - “Caminhar pelos próprios caminhos”...

Depois de reiterados processos de ocupação e colonização do seu território ancestral, de várias as tentativas de colonização espiritual e de imposição de práticas e instituições alheias à experiência da cultura própria, da ocupação e da perda do acesso aos seus lugares sagrados, e, mais recentemente, com o surgimento de múltiplos atores, interesses e planos encaminhados a explorar e planejar as questões do território da Serra Nevada de Santa Marta sem levar em consideração a existência e a perspectiva dos seus povoadores tradicionais, os povos Kogi, Wiwa, Arhuaco e Kankuamo insistem na necessidade de "caminhar pelos próprios caminhos".

Manifestamos ao governo que queremos ter, e fazer, educação escolar e programas de saúde, mas se eles ajudarem ao nosso próprio devir, se eles ajudarem a caminhar nosso próprio caminho, e se, também, [eles] ajudarem à gente da Serra [Nevada de Santa Marta] a vivenciar e lembrar-se da Lei de Origem. Não queremos progresso se a gente deve correr atrás do mundo civilizado. Temos nossos próprios caminhos e neles queremos caminhar, para o bem de todos (FAJARDO e GAMBOA, 1998, p. 246) ${ }^{2}$.

Insistir nos "caminhos próprios", de fato, não é uma questão nova na trajetória dos povos serranos. O apelo e os posicionamentos assumidos a favor da continuidade dos elementos que definem e dão coerência ao seu sentido de ser e de agir enquanto indígenas serranos têm sido para eles uma questão política de primeira ordem, que costura de maneira permanente as suas formas de relação com todos os atores interessados em ocupar o seu território ancestral ou em participar segundo seus interesses particulares - da realidade do maciço serrano.

A Lei de Origem ou Lei de Sé é justamente aquilo que é defendido como primordial para a existência dos povos indígenas da Serra Nevada. Ela é princípio, argumento de debate político, fundamento filosófico, forma de vida, sentido de existência; é a "autoridade" que legitima o próprio e diz respeito a qualquer pensamento e ação dos indígenas da

\footnotetext{
${ }^{2}$ Tradução livre de: "Al gobierno décimos que queremos tener, y hacer, educación escolar y programas de salud sólo si esto ayuda a nuestro propio devenir, si ayuda a andar nuestro propio camino, y si también ayuda a que la gente de la Sierra recuerde y viva la Ley de Origen. No queremos progreso si éste nos pone a andar detrás del mundo civilizado. Tenemos nuestros propios caminos y por ellos queremos caminar, para el bien de todos" (FAJARDO e GAMBOA, 1998, p. 246).
}

Espaço Ameríndio, Porto Alegre, v. 7, n. 1, p. 170-195, jan./jun. 2013. 
PATRÍCIA LORA LÉON - “Caminhar pelos próprios caminhos”...

Serra Nevada de Santa Marta. Portanto, é o "caminho próprio" que dá sustento ao exercício quotidiano da identidade indígena, que estrutura as formas organizativas próprias e define tanto os lineamentos na relação com os outros quanto o corpus da argumentação política que acompanha o atual momento político dos Kogi, Wiwa, Arhuaco e Kankuamo.

No documento Visão Ancestral Indígena para o Ordenamento Territorial da Serra Nevada de Santa Marta, os quatro povos guardiões do Coração do Mundo explicam que Sé não tem origem porque ele é tudo, é a origem de tudo quanto existe, é o princípio espiritual da existência. Sé materializa o mundo, organiza-o de tal maneira que ele mesmo é harmonia e equilíbrio. Sé é a passagem entre a luz e a escuridão, o limite entre o espiritual e o material.

Para nós o mundo foi primeiro em espírito (alúna), a ordem estabeleceu-se ali; tudo o que existe no mundo material, as plantas, os animais, a água (o mar, os rios, as lagoas, a neve), o fogo, o ar, a terra, os morros, as pedras e o homem, etc., existiram primeiro em espirito, eram como pessoas (aluna kággaba), tinham a mesma essência ou principio, eram espíritos da nossa grande mãe espiritual (aluna jaba) onde foi criado o universo material e onde foram ditadas as normas ou leis que regulamentam a função de cada elemento da natureza; assim, cada um destes seres espirituais recebe uma ordem, possui sua função, seu lugar, sua forma de estar, de viver, de construir, isto é, seu objetivo no mundo material (CTC, 2006, p. 4) ${ }^{3}$.

Sé opera no mundo irradiando ordem ao seu passo, estabelecendo o sentido dessa ordem e criando os códigos que permitem a coexistência da diversidade espiritual e material que constitui o universo. Uma ordem que deve ser preservada através dos códigos por ele criados no intuito de garantir o equilíbrio como princípio reitor de tudo quanto existe. Sé, através dos códigos consignados na Lei de

\footnotetext{
${ }^{3}$ Tradução livre de: "Para nosotros el mundo fue primero en espíritu (alúna), desde allí se estableció el orden, todo lo que existe en el mundo material, las plantas, animales, agua (mar, ríos, laguna, nieve), fuego, aire, tierra, cerros, piedras y el hombre, etc., existieron primero en espíritu, eran como personas (aluna kággaba), tenían la misma esencia o principio, eran espíritus de nuestra gran madre espiritual (aluna jaba) de donde se creó el universo material y de donde se dictan las normas o leyes que regulan la función de cada elemento de la naturaleza; así a cada uno de estos seres espirituales se les dio una orden, se les indicó una función, su lugar, su forma de estar, de vivir, de construir, es decir su objetivo en el mundo material" (CTC, 2006, p. 4).
}

Espaço Ameríndio, Porto Alegre, v. 7, n. 1, p. 170-195, jan./jun. 2013. 
PATRÍCIA LORA LÉON - “Caminhar pelos próprios caminhos”...

Origem, diz respeito à ligação permanente entre o material e o espiritual e à necessidade e importância de se estabelecer vínculos, acordos e pontes de comunicação entre os diferentes elementos que interagem no mundo e os pais e as mães espirituais "donos" dos princípios que regem a função de cada um desses elementos.

Assim como cada um dos pais e das mães espirituais, segundo a Lei de Origem, cumpre um objetivo na relação com o sentido de Sé enquanto princípio de tudo quanto existe, os indígenas, através das suas autoridades espirituais, têm a responsabilidade de conhecer cada um dos códigos reguladores dessa ordem e de realizar as práticas e os rituais necessários no intuito de conservar em harmonia os elementos espirituais e materiais que constituem o mundo.

Destarte, os indígenas consideram-se a si mesmos como os guardiões desse conhecimento, desses códigos que os seres espirituais, partindo de Sé, "escreveram" no "corpo" que serve de cenário ao conjunto de elementos que configuram esse universo material representado nos rios, nas árvores, nas plantas, nos animais e no próprio homem. A Serra Nevada de Santa Marta, o Coração do Mundo, é, portanto, o "corpo" que exprime os códigos da Lei de Origem, é a ponte material que possibilita a comunicação entre Sé como princípio espiritual da existência e a cultura própria como expressão a partir da qual os indígenas serranos garantem e vivificam o sentido dessa coexistência e ligação equilibrada entre o espiritual e o material. É, portanto, responsabilidade comum aos quatro povos guardiões da Serra Nevada o cuidado desses conhecimentos consignados no território e dos mecanismos a partir dos quais esses códigos adquirem expressividade no mundo através das práticas indígenas.

A cultura própria espelha-se no território, dele brotam os princípios que a orientam, e ao mesmo tempo nele reflete-se o funcionamento dinâmico que flui da prática permanente dos códigos orientadores da Lei de Origem. Nessa relação de mão dupla, é a cultura própria que provê a "conexão", a chave da comunicação com os espaços sagrados onde os pais e mães espirituais "habitam" e manifestam-se no mundo material, no território. Por meio das práticas xamanísticas, os Mamo ou autoridades espirituais, através do "pensamento", realizam os "trabalhos tradicionais" ou "pagamentos" que permitem "pagar" aos 
PATRÍCIA LORA LÉON - “Caminhar pelos próprios caminhos”...

"donos" espirituais de tudo quanto existe. Assim sendo, "pagar", na perspectiva da tradição, constitui um dos rituais fundamentais da cultura através do qual se oficiam as cerimônias necessárias para obter as "permissões" requeridas para a ação conjunta do homem com o mundo.

"Pagar" implica compreender a interligação essencial de todos os seres em qualquer ação possível de ser realizada no mundo e a necessidade permanente de respeitar as permissões e acordos que é preciso estabelecer com todos eles no intuito de manter o equilíbrio e evitar possíveis desequilíbrios. Os atos cerimoniais de pagamento executados pelos Mamo em cada um dos lugares de pagamento correspondentes a cada pai e mãe espiritual de cada existência no mundo cumprem, desta forma, com este quesito fundamental da cultura, constituindo-se numa prática constante que vivifica 0 significado dos lugares sagrados a onde se encaminha o trabalho tradicional. A Lei de Origem exerce-se desta maneira através de uma rede de espaços sagrados espalhados no território ancestral, adquirindo sentido e força só a partir da interconectividade que "ativa" a comunicação e ação conjunta entre o espiritual e o material que brota de Sé como fonte de tudo quanto existe.

A compreensão do sentido da cultura própria passa então pelo atrelamento dessa interligação essencial de todos os seres que compromete ativamente tanto a participação do território, que estabelece pontes de comunicação através dos lugares sagrados e das práticas xamanísticas de pagamento, como das comunidades, na celebração da vida como um todo. O que quer dizer que essa interligação que supõe a "inter-relação das partes" com um "todo", tanto na escala macrocósmica como na microcósmica, constitui ao mesmo tempo um modelo do "dever ser" da vida humana, no qual é atribuído ao indivíduo uma grande responsabilidade pessoal pelo fundamento do universo e de cada um dos seus componentes (REICHEL-DOLMATOFF, 1975).

A cultura própria, desta forma, não se expressa de maneira exclusiva na "força do pensamento" ou poder xamanístico do Mamo de comunicar-se com os pais e mães espirituais no intuito de "pagar" e "estabelecer acordos" com eles na ação conjunta no mundo, mas 
PATRÍCIA LORA LÉON - “Caminhar pelos próprios caminhos”...

também na comemoração cotidiana das quatro cerimônias de vida (nascimento, crescimento, casamento e mortuária), nas que revivificam e reconhecem a Sé como a Mãe Universa/ de tudo quanto existe.

Compreender a vida como um todo, como interligação essencial de todos os seres, para fazer possível qualquer ato de coexistência, coloca a cultura e, igualmente, o sujeito indígena ancorados numa destinação onde a existência só é possível de ser pensada no plural, na pluralidade das expressões espirituais e materiais que brotam da Mãe Universal. Isto dá ao sujeito indígena, na relação com a Lei de Origem, o status de cuidador desses códigos, atribuindo-lhe o papel de guardião dessa coexistência, ao tempo que o configura em si mesmo como "relação", como ponte de comunicação que dialoga com a diversidade de seres aos que reconhece como seus irmãos de existência (OGT, 1993).

Portanto, a relação com os outros, a coexistência que ela pressupõe, torna-se vital ao ponto de erigir-se numa "responsabilidade", num cuidado pelos outros que se assume como princípio de qualquer forma de convivência em e com o mundo. Por isso, eles consideram a si mesmos como os irmãos mais velhos, os que se apropriaram dessa responsabilidade de cuidado com o mundo e com a vida, os que compreendem a interligação essencial de tudo o que existe, e por esse caminho, possuem "conhecimentos" que "guardam" o segredo da comunicação que Sé estabelece entre o material e o espiritual. Os irmãos mais novos, os não indígenas e também os indígenas que não realizam as práticas nem cumprem com os princípios consignados na Lei de Origem, não levam em consideração, segundo eles, essa comunicação essencial que permite estender as pontes entre todos os elementos que existem e, nessa existência conjunta, transformar tudo o que acontece no mundo.

Formas próprias de caminhar e de perseverar na essência do próprio caminho

Assim como o pensamento cosmológico contorna os códigos originários da Lei de Origem, e a partir deles lhe dá à cultura própria uma expressão prática, é preciso também formas próprias de caminhar, 
PATRÍCIA LORA LÉON - “Caminhar pelos próprios caminhos”...

no intuito de perseverar na essência do próprio caminho. Esse caminhar, desde a perspectiva indígena, compromete os vários sentidos que envolvem o relacionar-se com o mundo e o potencial transformador que o sujeito indígena possui através da sua disposição de vincular-se e comunicar-se com a pluralidade espiritual e material que emana de Sé. Não se trata de um atributo ou uma potestade exclusiva que o coloca numa posição preferencial na relação com essa pluralidade do mundo, e sim, pelo contrário, de uma disposição particular para entrar em diálogo com esse mundo no intuito de possibilitar o agir conjunto e a coexistência equilibrada de todos os seres vinculados originariamente através da Mãe Universal.

Essa disposição que se torna vínculo e comunicação diz respeito àquilo que pauta as "formas de caminhar" do indígena serrano no marco do pensamento próprio: a ligação essencial entre o homem e a existência da vida no universo como um todo. Essa ligação torna-se ação e adquire expressão nos cenários quotidianos da cultura e nos espaços de encontro e negociação política com os representantes da sociedade nacional, através justamente de três princípios que direcionam permanentemente o agir indígena até a criação e recriação dessa comunicação essencial, da qual todas as formas de existência participam e são parte constitutiva: nas noções de yuluka, alúna e sewá é possível desvendar, desde a minha perspectiva, os fios que a comunicação essencial tece, ao ponto de configurar um espaço possível no qual o sujeito indígena projeta seu universo de relações para além de si mesmo, evidenciando os seus vínculos com a essência de todas as coisas e tornando-o, nesse caminho, em artífice da construção permanente da realidade compartilhada do mundo.

Gerardo Reichel-Dolmatoff (1985), através da experiência etnográfica com os Kogi, na década dos 60 do século passado, foi o primeiro a descrever a complexidade e polissemia destas categorias nas práticas religiosas e na vida cotidiana destas comunidades indígenas ${ }^{4}$. Considerando-as fundamentais na configuração do pensamento cosmológico e na realização dos rituais xamanísticos, destacou não só a

\footnotetext{
${ }^{4}$ Se bem o estudo de Reichel-Dolmatoff aborda propriamente o uso dessas categorias pelos informantes kogis, a minha experiência de pesquisa e os próprios documentos elaborados pelas lideranças espirituais e políticas serranas nas duas últimas décadas informam sobre ao apelo a esses conceitos e à sua importância no pensamento e a cultura própria tanto para os kogis quanto para os wiwas, arhuacos e kankuamos.
}

Espaço Ameríndio, Porto Alegre, v. 7, n. 1, p. 170-195, jan./jun. 2013. 
PATRÍCIA LORA LÉON - “Caminhar pelos próprios caminhos”...

importância delas, mas a inter-relação essencial que os informantes kogi lhes davam, colocando-as como elementos centrais na realização das suas práticas culturais.

As narrativas kogi, relatadas através do texto etnográfico de Reichel-Dolmatoff, levantam de forma recorrente uma preocupação indígena na relação com os outros, mas principalmente com o mundo sobrenatural: conscientes da interligação essencial que vincula tudo quanto existe, consideram vital o "estar de acordo" enquanto quesito que ao ser respeitado garante o pacto implícito de equilíbrio e convivência possível entre o material e o espiritual. Mas acordo, no sentido utilizado na perspectiva serrana, não remete necessariamente ao sentido de negociação ou de simplesmente concordar na procura de uma opinião consensual à qual poderíamos apelar desde o ponto de vista ocidental. Trata-se, para além dessa interpretação, de uma disposição frente aos outros que propende por um diálogo que compromete uma passagem imaginativa em direção à essência desse outro com o qual se pretende estabelecer uma relação, e nesse caminho, possibilizar a realização de qualquer ação no mundo compartilhado.

Os Kogi denominam essa passagem imaginativa como yuluka, que significa basicamente "estar igual" ou "da mesma espécie", num sentido de identificação. Quando o indígena está "de acordo" com alguma coisa, é ontologicamente igual, isto é, "faz parte da coisa e adquire as suas características". Esse "estar de acordo" alcança uma relevância fundamental na relação entre o mundo espiritual governado pelos pais e mães espirituais e as expressões materiais de Sé no mundo. No potencial acordo entre "donos" e possuidores dos códigos que dizem respeito ao funcionamento dos elementos da natureza, e dos seres, entre eles os humanos, que pretendem usufruí-los e realizar alguma atividade com esses elementos materiais ou através deles, emerge a chave que abre a porta de qualquer possível benefício ou infortúnio.

Quando o kogi diz: "as cobras são más; daí que é preciso estar de acordo com as cobras", quer dizer que, se identificando com a força maligna simbolizada na cobra, esta não pode Ihe fazer mal, senão considera ao individuo como seu "irmão", como da sua "família" e o protegerá. Nesta consideração subjaz o significado

Espaço Ameríndio, Porto Alegre, v. 7, n. 1, p. 170-195, jan./jun. 2013. 
PATRÍCIA LORA LÉON - “Caminhar pelos próprios caminhos”...

pleno das máscaras. Dançando com a máscara do aguaceiro, o dançarino está "de acordo" com o aguaceiro e adquire assim suas funções. Um dia, um kogi doente disse-nos: "eu penso como a doença". Quando disse isso, havia se identificado com a doença, estava de "acordo" com ela e não era mais sua vítima e sim seu dono (REICHEL-DOLMATOFF, 1985, p. 95) ${ }^{5}$.

O sentido da identificação joga aqui um papel fundamental. Não é possível entender o significado de yuluka sem apelar à experiência imaginativa que pressupõe entender a essência dessa existência, seja material ou espiritual, a forma como ela opera no mundo e a necessidade ontológica de estabelecer acordos com esses outros enquanto esses outros são constitutivos do próprio ser que se manifesta e atua na interligação com eles.

A necessidade de estabelecer pontes de comunicação no intuito de possibilitar esses cenários de diálogo surge, precisamente, da convicção de que essas relações não operam de maneira harmônica; pelo contrário, debatem-se permanentemente entre as forças opostas que atuam e determinam a ordem universal. De fato, a essência das diversas formas de existência, que é preciso "identificar" através da passagem imaginativa que yuluka possibilita, confirma, desde a perspectiva indígena, que o mundo opera mediante forças opostas, evidenciando assim o caráter contraditório, contingente e em permanente transformação da ordem natural.

Para os Kogi, a harmonia e a coexistência entre a diversidade espiritual e material é possível, e essa possibilidade emerge do reconhecimento desses opostos, da identificação da função que eles cumprem na constituição e configuração do mundo e na consciência do caráter complementário que essas forças possuem para configurar processos de equilíbrio entre as formas de existência presentes no universo. Daí que a passagem imaginativa que desde yuluka cria as

\footnotetext{
${ }^{5}$ Tradução livre de: "Cuando el kogi dice: "las culebras son malas; por eso hay que estar de acuerdo con las culebras", entonces quiere decir que, identificándose con la fuerza maligna simbolizada en la culebra, ésta no le puede hacer daño sino considera al individuo como "hermano", como de la "familia" y lo protegerá. Sea dicho que en esta consideración yace todo el significado de las máscaras. Bailando con la máscara del aguacero, el bailador está "de acuerdo" con el aguacero y adquiere así las funciones de éste. Un kogi enfermo nos dijo un día: "yo pienso como la enfermedad". Cuando dijo eso, se había identificado con la enfermedad, estaba "de acuerdo" con ella y ya no era su víctima sino su dueño" (REICHELDOLMATOFF, 1985, p. 95).
}

Espaço Ameríndio, Porto Alegre, v. 7, n. 1, p. 170-195, jan./jun. 2013. 
PATRÍCIA LORA LÉON - “Caminhar pelos próprios caminhos”...

pontes de comunicação entre essas forças opostas cumpre uma função essencial para garantir o que desde a perspectiva cosmológica serrana constitui o sentido do ser do homem na relação com o mundo. Segundo Reichel-Dolmatoff,

Os kogi acreditam na existência de um princípio do bem (direito), cuja permanência e função benéfica estão determinadas pela existência simultânea de um princípio do mal (esquerdo). Assim, para garantir a existência do bem é preciso fomentar o mal, dado que, no caso deste desaparecer por não achar uma justificação da sua existência, eliminaria, por sua vez, o bem. Logo é necessário que o indivíduo cometa pecados que testemunhem a influencia ativa do mal. Eis onde subjaz, segundo os kogi, o principal problema da condição humana: em equilibrar estas forças opostas, mas complementárias, e em estabelecer entre ambas as forças uma relação harmônica (REICHELDOLMATOFF, 1966, p. 10$)^{6}$.

Assim sendo, a condição humana ancora-se no poder de equilibrar as energias produtivas e destrutivas, no "estar de acordo" e no sentido da comunicação como princípio de qualquer relação, que se expressa na cultura e manifesta-se tanto nos rituais xamanísticos quanto na cotidianidade das práticas politicas e sociais das comunidades.

No plano xamanístico, o acordo e a identificação operam com a mediação do Mamo, possuidor dos conhecimentos e das permissões necessárias para fundar acordos com os pais e as mães espirituais, sendo o pagamento uma das máximas expressões que na cultura dizem respeito à capacidade do sujeito de estabelecer pontes de comunicação entre o material e o espiritual, partindo do reconhecimento da função que uns e outros cumprem no agir conjunto para a realização harmônica de qualquer empreendimento. Nas dinâmicas internas da cultura, o acordo privilegia a conversa e a discussão coletiva sobre qualquer

\footnotetext{
6 Tradução livre de: "Los kogi creen en la existencia de un principio del bien (derecho) cuya permanencia y función benéfica está determinada por la existencia simultánea de un principio del mal (izquierdo). Así, para asegurar la existencia del bien es necesario fomentar el mal ya que, si este desapareciese, por no encontrar una justificación de su existencia, se eliminaría al mismo tiempo el bien. Es necesario pues que el individuo cometa pecados que atestiguen la influencia activa del mal. Es aquí donde yace, según los kogi, el principal problema de la condición humana: en equilibrar estas dos fuerzas opuestas pero complementarias, y en establecer entre estas una relación armónica" (REICHEL-DOLMATOFF, 1966, p. 10).
}

Espaço Ameríndio, Porto Alegre, v. 7, n. 1, p. 170-195, jan./jun. 2013. 
PATRÍCIA LORA LÉON - “Caminhar pelos próprios caminhos”...

aspecto da vida política e social das comunidades, abrindo passo a prolongadas jornadas de ritualização da palavra como expressão do pensamento e da escuta, como pensamento que se encaminha no rumo da reflexão.

Esse princípio de comunicação entre os opostos no intuito de harmonizar a ordem universal, destacado por Reichel-Dolmatoff como uma peça constitutiva do sistema religioso dos Kogi, é na realidade um princípio de relação próprio dos quatro povos indígenas da Serra Nevada de Santa Marta. Mesmo que ele não apareça nomeado como yuluka na tradição oral dos outros três povos e nos documentos políticos redigidos conjuntamente nos últimos anos, o sentido de "comunicar", "estar de acordo", de "compor", "arranjar", "harmonizar", enfim, "pôr em ordem", aparece recorrentemente evidenciando a necessidade de "pensar como" e de "fazer parte daquilo com o que se pretende dialogar", no propósito de criar verdadeiros espaços para a comunicação e para a criação de vínculos em e com o mundo.

\section{"Ver de duas formas": a chave de comunicação em e com o mundo}

Se bem o propósito da comunicação entre os opostos materializase na realização do pagamento enquanto mecanismo ritual que garante a harmonização entre o mundo espiritual e material e privilegia o diálogo como pauta de relacionamento nas práticas cotidianas das próprias comunidades, ainda é preciso desvendar mais elementos que nos possibilitem compreender os dispositivos a partir dos quais yuluka opera como um princípio fundamental através do qual o sujeito indígena consegue tornar-se a ponte de comunicação e expressão da comunicação essencial entre o humano e a essência de todas as coisas.

Yuluka, na minha perspectiva, é o elemento do pensamento próprio dos povos indígenas da Serra Nevada de Santa Marta que expressa com maior claridade o papel do sujeito indígena na comunicação com as outras formas de existência (para além dos vínculos que o Mamo estabelece através das práticas xamanísticas de pagamento). Em yuluka é possível tanto harmonizar as forças positivas e negativas que alternam no cenário das vivências humanas, como honrar 
PATRÍCIA LORA LÉON - “Caminhar pelos próprios caminhos”...

o processo permanente de construção da vida como um todo, através do cumprimento da responsabilidade do indivíduo e da comunidade de seres, garantindo esses vínculos entre o espiritual e o material que emanam de Sé. Sem essa comunicação, sem a prática individual ou coletiva de yuluka, o desequilíbrio, a incompreensão, a destruição, a violência, os conflitos e as doenças humanas e da natureza afloram como prova da quebra entre essas duas formas de existência - a espiritual e a material - que organizam o mundo.

É por isso que os Kogi asseguram que existem duas formas de ver as coisas: como elas aparecem através da nossa experiência dos sentidos no universo material, mas também na dimensão de como elas existem na sua essência espiritual. Portanto, para estabelecer as pontes de comunicação entre o homem e o mundo através de yuluka, e nesse caminho procurar e fundar acordos, é preciso ver de duas formas: "ver" tanto o alúna daquilo com o que se pretende dialogar, como a expressão que esse alúna adquire no mundo material. A Serra Nevada de Santa Marta não escapa a esta máxima do pensamento indígena: ela é "pensamento e realidade", o que quer dizer que ela deve ser vista tanto na concretude do real, que se expressa na materialidade do território, mas ao mesmo tempo desde a essência "verdadeira", isto é, desde o significado profundo que ela possui desde a dimensão cosmológica, na qual ela é depositária dos códigos que orientam o sentido de ser e de agir enquanto indígenas a partir dos preceitos da Lei de Sé.

Essa máxima opera como um mecanismo de compreensão da realidade, como o quesito sem o qual não é possível levar em consideração a essência da existência, com a qual é necessário chegar a um acordo para garantir o equilíbrio universal. Vendo de duas formas, o pensamento serrano incorpora nas suas formas de compreensão da realidade as forças opostas entre as quais debate-se o destino humano (Material/espiritual, positivo/negativo, masculino/feminino, vida/morte, e assim por diante), e nesse "olhar profundo" (RUBIO SERRANO, 1997) pressentificam sempre o sentido que desde a sua cosmovisão possui a dimensão espiritual que diz respeito à essência de todas as coisas, isto é, de alúna como pilar da cultura serrana.

$\mathrm{Na}$ tentativa de traduzir para a língua espanhola a complexidade 
PATRÍCIA LORA LÉON - “Caminhar pelos próprios caminhos”...

da palavra alúna e as múltiplas expressões que dela advém no dia a dia da cultura, os Kogi a descrevem ao mesmo tempo como "espírito, memória, pensamento, vida, alma, intenção ou vontade" (REICHELDOLMATOFF, 1985, p. 95); palavras que por si só, segundo ReichelDolmatoff, não dão conta da profunda significação que alúna tem enquanto peça chave do acontecer indígena.

Para os indígenas serranos, alúna ${ }^{7}$ expressa em si mesma a faculdade do pensamento e do pensar. Sendo invisível, alúna presentifica o ausente e possibilita a comunicação com o espiritual (ou o alúna de cada uma das expressões de Sé no mundo material), através da experiência da retirada do mundo mediada pelo ato ritual que consiste na concentração e meditação do indivíduo, alternada pela repetição de uma frase pensada, ou de danças e cantos, quando isso acontecer de maneira coletiva. Assim o Mamo consegue realizar o pagamento e abre passo aos possíveis acordos através da força do seu pensamento 8 . Alúna, no sentido de pensar, remete-se também à capacidade do indivíduo de refletir e de decidir, de viver em alúna, e, nesse sentido, entender que essa faculdade permeia cada um dos vínculos que estabelece com os outros e o próprio potencial de celebrar acordos no intuito de honrar a comunicação essencial que o liga com tudo o existente, com a vida mesma.

Mas as narrativas kogi descrevem também o sentido de alúna como aquilo que cria e transforma, como a potência que em si mesma torna-se possibilidade afetando o mundo, tanto positiva como negativamente. Aliás, para os indígenas da Serra Nevada de Santa Marta, o mundo foi criado em alúna, e ele é permanentemente recriado através do pensamento, isto é, em alúna, nas formas como o indígena concebe e projeta cada uma das ações que realiza no seu dia a dia. Daí que a relação com os outros se realiza sempre em alúna, isto é, visando o universo de possibilidades que dessa relação advém, e, assim sendo, leva necessariamente em consideração o alúna desses outros com os quais o mundo transforma-se permanentemente.

Alúna, neste sentido, é também um atributo, é aquilo que os seres

\footnotetext{
${ }^{7}$ Alúna, no kogian (língua kogi), ruama, no damana (língua wiwa), arunamu, no ikun (língua arhuaca).

${ }^{8}$ Essa expressão refere-se na visão serrana precisamente à forma de comunicação espiritual, isto é, em alúna, com a qual o xamã consegue estabelecer a ligação em alúna com as múltiplas existências que interagem no mundo.
}

Espaço Ameríndio, Porto Alegre, v. 7, n. 1, p. 170-195, jan./jun. 2013. 
PATRÍCIA LORA LÉON - “Caminhar pelos próprios caminhos”...

possuem e que se torna parte constitutiva de sua essência. Poder-se-ia traduzir como espírito, e de alguma forma alúna apela exatamente ao reconhecimento dessa essência espiritual que faz parte do ser de cada existência material. Sendo ela constitutiva e originária, alúna, enquanto expressão de Sé, é, na perspectiva kogi, o que possui verdadeiro valor e dá sentido à existência. O que chamamos de realidade, visível e percebível aos sentidos, é para eles a simbolização do que é verdadeiro, da essência do alúna, que diz respeito à ligação fundamental que desde Sé vincula o material com os verdadeiros pais e mães "donos" de tudo quanto existe $^{9}$.

Diante da polissemia que a expressão alúna possui no universo cosmológico kogi e dos outros povos serranos é preciso compreender a diversidade dos significados que na experiência indígena ela apresenta de forma simultânea, criando e recriando sempre as formas que esses sentidos adquirem na múltipla conotação de pensamento, criação e existência espiritual. Nos relatos sobre a criação do mundo, por exemplo, encena-se a presença espiritual da Mãe Universal como geradora de vida no sentido de criadora e como fonte de transformação possível através do pensamento.

Primeiro estava o mar. Tudo estava escuro. Não havia sol, nem lua, nem gente, nem animais, nem plantas. $O$ mar estava por todas partes. O Mar era a Mãe. A Mãe não era gente, nem nada, nem coisa nenhuma. Ela era alúna. Ela era espírito do que viria e ela era pensamento e memória. Assim a mãe existiu só em alúna, no mundo mais baixo, no mais profundo, sozinha (REICHEL-DOLMATOFF, 1985, p. 17) ${ }^{10}$.

E assim em diante, todos os pais e mães que nascem desde a Mãe Universal são o alúna que virá ser em alúna, isto é, espírito e pensamento e também fonte infinita de criação de vida. Nesse ritual infinito de celebração e revitalização da criação desde Sé, que a Lei de Origem orienta e a cultura própria dinamiza, espírito, pensamento e

\footnotetext{
${ }^{9}$ Daí que para eles a Serra Nevada de Santa Marta seja pensamento e realidade, como já foi explicado anteriormente.

10 Tradução livre de: "Primero estaba el mar. Todo estaba oscuro. No había sol, ni luna, ni gente, ni animales, ni plantas. Solo el mar estaba en todas partes. El Mar era la Madre. La Madre no era gente, ni nada, ni cosa alguna. Ella era alúna. Ella era espíritu de lo que iba a venir y ella era pensamiento y memoria. Así la madre existió sólo en alúna, en el mundo más bajo, en la última profundidad, sola" (REICHEL-DOLMATOFF, 1985, p. 17).
}

Espaço Ameríndio, Porto Alegre, v. 7, n. 1, p. 170-195, jan./jun. 2013. 
PATRÍCIA LORA LÉON - “Caminhar pelos próprios caminhos”...

criação adquirem significação permanente desde alúna. Não operam como sinônimos, mas seus atributos se justapõem para de alguma forma dar conta do sentido total que alúna possui no universo simbólico dos indígenas da Serra Nevada de Santa Marta, sendo essa tríplice potencialidade a fonte que possibilita não só ao povo Kogi, mas também aos Arhuaco, Kankuamo e Wiwa acessar os conhecimentos que thes permitem estabelecer a comunicação com a vida como um todo.

Conhecimentos e pensamentos são em si mesmos canais de comunicação, mas possuem funções distintas e aparecem claramente diferenciados desde a perspectiva indígena. Aqui novamente a realidade é vista de duas formas: enquanto o pensamento (alúna) não deixa rastro no mundo material - ele sempre é possibilidade de transformação e lembrança da essência verdadeira da pluralidade existente -, os conhecimentos, pelo contrário, existem desde sempre nos códigos da Lei de Origem, adquirem uma dimensão simbólica na materialidade do mundo e eles são a expressão do "compromisso" de cuidado que o indígena recebe no seu vínculo originário com Sé. Na Declaração conjunta das organizações indígenas da Serra Nevada para a interlocução com o Estado e a Sociedade Nacional, os indígenas serranos destacam os sewá enquanto esses símbolos do espiritual, capazes de criar e recriar esse vínculo que lembra na sua materialidade os acordos celebrados e a "responsabilidade" de velar permanentemente pelo cumprimento do que foi delegado e entregue ao seu cuidado através deles.

Sewá provem de Sé. Quando nascemos nos entregam nosso primeiro sewá. Depois, quando recebemos o poporo, entregam-nos o segundo sewá ou marunsuma, e é esse o que nos dá a responsabilidade, o que nos monstra o caminho. Ele é o guia para manter contato com a Mãe e o Pai Espiritual. Igualmente, para poder fazer os trabalhos, desde tombar uma árvore até as tarefas mais complexas que realizam os nossos Mama [mamo], recebemos os sewá correspondentes que nos permitem cumprir a nossa missão. Sewá dispõe materialmente as leis entregues desde o princípio, as leis de Sé, aquelas que desde a época da escuridão traçaram o caminho para nós (CTC, 1999, p. 23) ${ }^{11}$.

11 Tradução livre de: "Sewá viene de Sé. Apenas nacemos nos entregan nuestro primer sewá. Luego, cuando recibimos el poporo, nos entregan el segundo sewá o marunsuma, y éste es el que nos da

Espaço Ameríndio, Porto Alegre, v. 7, n. 1, p. 170-195, jan./jun. 2013. 
PATRÍCIA LORA LÉON - “Caminhar pelos próprios caminhos”...

O sewá, ou marunsuma12, é algo que se recebe, que é entregue ao indígena após a passagem que vai da comunicação prévia com as mães e os pais espirituais à simbolização do seu "conteúdo" em expressões materiais da cultura. O poporol3, os quartzos, os fios de algodão, conchas, diferentes pedras e minerais, são exemplos de objetos que dizem respeito tanto à autoridade espiritual, que tem a potestade de permitir a realização de qualquer empreendimento, quanto ao compromisso "eterno", que assume quem recebe esse poder através desse objeto, de torná-lo uma constante de seu agir ao revivificá-lo através da continuidade do conhecer, que permite sua atualização no acontecer cotidiano indígena.

Receber o sewá ou marunsama implica um
compromisso eterno com as leis e os sistemas de
comportamento que nos identificam como indígenas.
[receber o sewá] É assumir uma responsabilidade com
o coletivo social e natural da nossa cultura e, em geral,
com a vida como um todo. O sewá ou marunsuma
representa e simboliza a abertura a uma missão
encomendada, sem ele, é impossível um resultado
satisfatório e de acordo com as nossas normas de
convivência. O desconhecimento do sewá ou o uso
ignorante dele nos acarretaria conflitos e doenças.
Ademais, o sewá ou marunsuma não é temporal nem
transitório, é a realização das normas através do
seguimento, a continuidade, a disciplina e o
compromisso (CTC, 1999, p. 24) ${ }^{14}$.

responsabilidad, nos muestra el camino. Es la guía para tener contacto con la Madre y el Padre Espiritual. Igualmente, para poder ejercer los trabajos desde tumbar un árbol hasta llegar a las tareas más complejas que realizan nuestros Mama, se reciben los respectivos sewá que nos permiten dar cumplimiento a nuestra misión. Sewá nos coloca en lo material las leyes entregadas en el principio, las leyes de Sé, aquellas que desde la época de la oscuridad nos trazaron el camino" (CTC, 1999, p. 23).

12 Sewá na língua kogi e marunsuma na língua arhuaca

${ }^{13}$ Objeto sagrado utilizado pelos homens. Trata-se de um pequeno recipiente de calabazo na forma de relógio de areia, no qual os indígenas da Serra Nevada guardam pó de cal com o propósito de ingeri-lo misturado com folhas de coca.

14 Tradução livre de: “"El recibir sewá, o marunsama implica un compromiso eterno con las leyes y los sistemas de comportamiento que nos identifican como indígenas. Es asumir una responsabilidad con la colectividad social y natural de nuestra cultura y en general con el conjunto de la vida. El sewá o marunsuma representa y simboliza la apertura de una misión encomendada, sin él es imposible que exista un resultado satisfactorio e acorde con nuestras normas de convivencia. Sin el conocimiento del sewá o el uso basado en la ignorancia que de él se tenga, nos llevará a conflictos y enfermedades. Es más, el sewá o marunsuma no es temporal ni transitorio, es la puesta en práctica de las normas por medio del seguimiento, la continuidad, la disciplina y el compromiso" (CTC, 1999, p. 24).

Espaço Ameríndio, Porto Alegre, v. 7, n. 1, p. 170-195, jan./jun. 2013. 
PATRÍCIA LORA LÉON - “Caminhar pelos próprios caminhos”...

O "uso" que o indígena faz de cada um dos elementos necessários na realização de qualquer atividade implica, no intuito de "receber" o correspondente sewá, a execução desse movimento que passa pela comunicação ao "dono" espiritual desse elemento e do 'dono' da atividade a ser realizada. Reichel-Dolmatoff descreve que, no caso dos Kogi, por exemplo, para construir uma casa nova, é preciso "obter os sewâ", isto é, as permissões, para participar da essência de cada um dos elementos a utilizar e finalmente fazer o próprio com o sewá equivalente à atividade de construir.

Nesse caminho é possível garantir que o equilíbrio dos elementos que agem de maneira conjunta no mundo afetando-se uns aos outros não se veja seriamente prejudicado. O mesmo acontece em cada fase do ciclo da vida do indivíduo e nas cerimônias próprias de cada um desses momentos (batizo para o nascimento, entrega do sewá do poporo no início da fase reprodutiva, matrimônio e mortuária), assim como na participação indígena nos processos de criação e reprodução da vida, principalmente as coletas: é preciso obter os sewá e através deles dar continuidade ao ritual que vivifica a comunicação entre o material e o espiritual que emana de Sé.

$\mathrm{Na}$ língua kogi, explica Reichel-Dolmatoff, a palavra sewá é utilizada também para expressar o sentido de esposo e esposa: o marido é o sewá da mulher e ela é o sewá do seu marido. Para os Kogi, segundo a análise do autor, o matrimônio é a máxima simbolização de todos os sewá possíveis; na relação entre homem e mulher, masculino e feminino, emerge o mesmo princípio que possui qualquer sewá e a atividade que este representa: o princípio da comunicação, que desde yuluka lembra a responsabilidade do sujeito indígena de estabelecer e recriar de maneira permanente os vínculos entre as forças opostas que determinam o destino humano, para assim alcançar, mediante o acordo, o equilíbrio universal.

O sewá simboliza, então, a ligação permanente entre o material e o espiritual. Através do poder de "conhecer" ou no "título de conhecimento" que advém dessa comunicação e consulta, o sewá simboliza "os acordos" estabelecidos com as diferentes expressões materiais que existem. Também pode ser considerado em si mesmo como memória, como a lembrança constante da responsabilidade 
PATRÍCIA LORA LÉON - “Caminhar pelos próprios caminhos”...

indígena no cuidado da essência de todas as coisas e na manutenção dos canais de comunicação que tornam possível o equilíbrio entre os opostos. Daí que a forma indígena de "conhecer" não passa pela pretensão de fixar e controlar o universo material, desde sempre criado e organizado mediante os códigos que emanam da Lei de Origem. Sua única pretensão é a de ser partícipe do processo da vida, comunicandose permanentemente com o sentido espiritual originário que compartilha com cada elemento que existe no mundo, guardando os códigos que lhes foram entregues desde o começo dos tempos e celebrando os rituais necessários que o ressignificam permanentemente através do pensamento, do acordo, da comunicação, da criação e do reconhecimento da interligação essencial de tudo.

\section{Os caminhos da comunicação com o irmão mais novo}

A importância da comunicação para o pensamento e a cultura própria, como explicitado anteriormente, evidencia-se, portanto, na ideia do acordo e da ligação possível e necessária com o mundo através de yuluka, na participação nele da essência espiritual de todas as coisas (alúna) e das expressões que no mundo material simbolizam essa comunicação e a responsabilidade que dela subjaz (sewâ). Mas o que acontece quando esses princípios são expostos à diversidade complexa e constitutiva do mundo que existe para além das fronteiras estabelecidas pela cultura? Que ocorre quando a presença dos não indígenas no seu território ancestral afeta a realização das práticas culturais necessárias para manter essa comunicação? Como encarar o inevitável encontro com o "outro" sem abrir mão desses princípios que dizem respeito ao seu sentido de ser e de agir enquanto indígenas serranos e, ao mesmo tempo, aos fundamentos necessários para a existência da vida como um todo?

Uma resposta possível para estas questões encontra-se numa outra interpretação que Reichel-Dolmatoff faz sobre a importância que para os Kogi tem "os dois modos de ver as coisas". Segundo o autor, "ver de duas formas" significa também entender que - no meio das tensões que advêm da existência de forças opostas no destino humano 
PATRÍCIA LORA LÉON - “Caminhar pelos próprios caminhos”...

e na ordem natural e para além delas - a ambivalência e a contingência fazem parte do acontecer humano, e assim sendo, "o objeto da existência humana consiste em encontrar um equilíbrio entre a multiplicidade de fenômenos que rodeiam ao individuo" (REICHELDOLMATOFF, 1975, p. 174). Isto é, que diante da contingência e dos riscos que afetam a continuidade desses princípios é possível "ver" sempre alternativas e formas criativas para estabelecer novos canais e formas de comunicação com esses "outros".

[...] Como o irmão mais novo não sabe comunicar-se em alúna (em espirito) é preciso cadastrar a comunicação por escrito através de uma carta ou de uma ata da reunião realizada nos escritórios [governamentais]. Neste sentido, é necessário não só falar o espanhol, também lê-lo e escrevê-lo com o propósito de tramitar as necessidades dos povos da Serra; [...] É neste ponto no qual observamos como a vida interna dos homens de branco e poporo criam vasos comunicantes com o mundo externo e precisam das ações realizadas pelo irmão mais novo nas zonas urbanas da Serra para assim conseguir estar de acordo com tudo o que o rodeia, para estar em yuluka (RUBIO SERRANO, 1997, p. 54) ${ }^{15}$.

Trata-se, na leitura de Rubio (1997, p. 174), de fundar uma "nova ordem social" na qual os alicerces políticos das organizações indígenas serranas e os textos que, baseados nesses fundamentos, costuram esse "duplo propósito" de dar continuidade aos princípios ancorados na Lei de Origem e a partir dele criar "outras" formas de configuração da relação com os diferentes atores participantes da realidade do seu território ancestral, pretendem pautar tanto os conteúdos como os termos da conversação entre o "mundo de interna" e o "mundo de externa".

Esse propósito evidencia-se claramente na conformação da organização Gonawindúa Tayrona em 1987. Estrutura criada para a

15 Tradução livre de: “““[...] como el hermanito menor no sabe comunicarse en alúna (en espíritu) es necesario radicar la petición por escrito mediante una carta o el acta de reunión sostenida en las oficinas. En este sentido, no sólo es necesario saber hablar español, sino también leerlo y escribirlo con el objeto de tramitar las necesidades de los pueblos de la Sierra; [...]. Es en este punto dónde observamos cómo la vida interna de esos hombres de blanco y poporo crea vasos comunicantes con el mundo de externa y precisa de las acciones adelantadas por los hermanos menores en los cascos urbanos de la Sierra para poder estar de acuerdo con todo lo que los rodea, para llegar a yuluka" (RUBIO SERRANO, 1997, p. 54).

Espaço Ameríndio, Porto Alegre, v. 7, n. 1, p. 170-195, jan./jun. 2013. 
PATRÍCIA LORA LÉON - “Caminhar pelos próprios caminhos”...

relação com os não indígenas, constituída por comunidades kogi, wiwa e arhuaca da vertente norte da Serra Nevada e precedida pela experiência de outras propostas organizativas lideradas por comunidades do povo Arhuaco ${ }^{16}$, Gonawindúa Tayrona expressa a razão de ser do indígena serrano orientando seu propósito e ações no marco da Lei de Origem e, assim sendo, veicula uma "dupla forma" de participação das comunidades indígenas serranas na pauta política do território da Serra Nevada de Santa Marta, colocando o pensamento e a cultura próprias em diálogo e relação com a realidade regional, nacional e global.

Com a constituição de Gonawindúa Tayrona, assim como com as outras organizações indígenas dos diferentes povos que surgem na década seguinte ${ }^{17}$, a reconfiguração política dos indígenas serranos aponta para este "duplo propósito" nos espaços de negociação política que afloravam no marco da proliferação de iniciativas de intervenção ${ }^{18}$ no território da Serra Nevada. Assim, este episódio marca um momento único na projeção desse pensamento cosmológico para além das fronteiras da cultura própria, criando os vasos comunicantes para uma comunicação possível, na qual o pensamento que dá sentido à existência dos povos serranos e da própria humanidade seja realmente levado em consideração.

Logo, este importante movimento que emerge da reconfiguração e do posicionamento político dos quatro povos guardiões do coração do mundo diz respeito à necessidade de serem escutados e compreendidos na dimensão do que para eles constitui o sentido de sua existência e os princípios que sustentam um pensamento e uma forma de relação em e com o mundo. Nesse caminho, torna-se fundamental explicitar aos irmãos mais novos que eles existem enquanto cuidadores e guardiões do seu território ancestral, e que a relação por eles estabelecida com esse território compromete uma visão compartilhada por quatro povos

\footnotetext{
${ }^{16}$ Primeiro foi a Liga Indígena da Serra Nevada, vinculada com a Federação de Trabalhadores do Magdalena, em 1931. Logo, o Conselho e Organização Indígena Arhuaca (COIA), em 1974, e finalmente a Confederação Indígena Tayrona (CIT), em 1983.

${ }^{17}$ A Organização Wiwa Yugumaiun Bunkwanarrwa Tayrona (OWYBT) e a Organização Indígena Kankuama (OIK). Finalmente, em 1999, nasce o Conselho Territorial de Cabildos (CTC) como máxima expressão da unidade organizativa e política dos quatro povos serranos.

${ }^{18}$ Entre elas o Plano de Desenvolvimento Sustentável da Serra Nevada de Santa Marta, liderado pelo governo nacional e pela Ong Fundación Pro-Sierra Nevada de Santa Marta, e a recente investida de megaprojetos de desenvolvimento, entre eles várias barragens, projetos turísticos e portos multipropósito.
}

Espaço Ameríndio, Porto Alegre, v. 7, n. 1, p. 170-195, jan./jun. 2013. 
PATRÍCIA LORA LÉON - “Caminhar pelos próprios caminhos”...

indígenas que possuem um pensamento próprio, umas práticas culturais comuns e umas formas de ação política que encerram dinâmicas próprias a serem levadas em consideração no diálogo e negociação com os outros interessados em participar e decidir sobre o destino da Serra Nevada de Santa Marta.

Esse alvo, traçado inicialmente com a conformação da organização Gonawindúa Tayrona, contorneia-se com maior precisão com o surgimento, em 1999, do Conselho Territorial de Cabildos (CTC), órgão que no político expressa o propósito de unidade das autoridades espirituais e políticas dos quatro povos serranos. Através dos documentos e declarações conjuntas emitidas desde este importante cenário, os indígenas da Serra Nevada levam adiante seu propósito de comunicar "por si mesmos" a complexidade do pensamento próprio e das práticas culturais que dão sentido a sua existência enquanto povos. Nesses documentos, numa ação conjunta de "tradução" entre os Mamo e as lideranças das organizações indígenas, emergem textos que costuram as "categorias indígenas de pensamento" com os termos "ocidentais" necessários no diálogo com o "Estado e a sociedade nacional".

A complexidade do pensamento próprio e das "categorias" nele imbuídas é então apresentada através de diferentes documentos políticos. Nesses documentos mostra-se a Sé como princípio espiritual da existência, a Lei de Origem e a cultura própria como códigos orientadores do pensamento e ação indígenas, o território da Serra Nevada como o cenário onde esses códigos foram escritos pelos pais e mães espirituais, os pagamentos como expressão fundamental da cultura e a Linha Negra como um marco central no processo de negociação de qualquer intervenção no seu território ancestral 19 .

Nesses documentos, a importância da comunicação "verdadeira" entre o mundo e a sua essência perpassa a visibilização dessas

\footnotetext{
${ }^{19} \mathrm{O}$ reconhecimento jurídico da Linha Negra como limite do território ancestral dos povos indígenas da Serra Nevada de Santa Marta pelo Estado colombiano, através das Resoluções 0002, de 4 de janeiro de 1973, e 837, de 1995, do Ministério do Interior e da Justiça, é um caso único na legislação do país. Nesses documentos, o Estado colombiano reconhece "os limites da reserva simbólica" que constituem os diferentes pontos sagrados interligados que contornam o maciço montanhoso, e autoriza aos Mamo, como autoridades espirituais, o acesso aos lugares sagrados para realizar os rituais de "pagamento" que, no marco da Lei de Origem, permitem a comunicação com os pais e as mães espirituais e o acesso aos conhecimentos tradicionais escritos no território.
}

Espaço Ameríndio, Porto Alegre, v. 7, n. 1, p. 170-195, jan./jun. 2013. 
PATRÍCIA LORA LÉON - “Caminhar pelos próprios caminhos”...

"categorias" como peças constitutivas do pensamento e a cultura próprias. Daí a preocupação permanente, evidenciada no documento Difusão e consulta do ordenamento territorial, de colocar como uma questão fundamental do seu ser e agir enquanto povos a permanência, e, junto a ela, o respeito, dos canais e formas de comunicação que a cultura tem estabelecido e privilegiado no intuito de garantir os acordos entre as forças opostas que atuam no mundo.

Nosso território é um conjunto de comunicação e de entendimento expressivo e simbólico, interpretativo e sensitivo de caráter inefável. Portanto [o território] é de significado transcendental tanto para a visão humana quanto para a visão espiritual junto com o pensamento, a vontade e o querer do indígena encarregado de cuidar nossa mãe terra como a morada materna de todos os povos indígenas que nele existimos. Toda a realidade histórico-cultural da Serra Nevada de Santa Marta foi violentada e usurpada pela invasão europeia, tirando-nos o direito à territorialidade e profanando os nossos lugares sagrados e os nossos recurso naturais que são, ao mesmo tempo, irmãos de existência (OGT, 1993 , p. 10$)^{20}$.

$\mathrm{Na}$ atual conjuntura, essa "comunicação verdadeira" adquire uma relevância ainda maior. A "incompreensão" das suas práticas culturais e da coerência que elas têm na interligação essencial de tudo quanto existe tem levado tanto ao desconhecimento da sua participação como povos originários nas ações a serem realizadas no seu território ancestral, quanto ao enfraquecimento dessa comunicação essencial que afeta não só o equilíbrio da Serra Nevada, mas a existência da vida como um todo.

Os tempos não os mesmos, [não são] como faz 500 anos quando começou o contato e o irmão mais novo intrometeu-se no nosso território e no nosso destino. Muitas coisas têm mudado, por exemplo, temos perdido

\footnotetext{
20 Tradução livre de: "Nuestro territorio es un conjunto de comunicación y entendimiento expresivo y simbólico, interpretativo y sensitivo de carácter inefable. Por lo cual es de significado trascendental tanto para la visión humana como para la visión espiritual junto al pensamiento, la voluntad y el querer del indígena encargado de cuidar nuestra madre tierra como morada materna de todos los pueblos indígenas que en ellos existimos. Toda la realidad histórica cultural de la Sierra Nevada de Santa Marta fue violentada y usurpada por la intromisión europea quitándonos el derecho a la territorialidad y profanando nuestros lugares sagrados y nuestros recursos naturales que son también hermanos de existencia..." (OGT, 1993, p. 10).
}

Espaço Ameríndio, Porto Alegre, v. 7, n. 1, p. 170-195, jan./jun. 2013. 
PATRÍCIA LORA LÉON - “Caminhar pelos próprios caminhos”...

boa parte dos sítios sagrados fundamentais para a reprodução da lei de Seynekun, que é a reprodução da natureza mesma e da cultura. Isto não é um problema de alguns índios teimosos; trata-se de um problema que diz respeito à humanidade toda. Por que a gente diz isso? A Serra Nevada é o coração do mundo, aqui estão as origens de tudo quanto existe; seguindo a lei de Sé, continuamos espiritualmente revitalizando a vida, fazemos à prática - até onde nos é possível - de nos comunicar com os Pais espirituais de todos e cada um dos seres que constituem a vida. Infelizmente, tem se perdido muitos dos sítios necessários para continuar a nossa missão, ou não temos mais acesso, ou eles vem se deteriorando pela concepção de desenvolvimento (cada vez mais errada) do irmão mais novo (OGT, 1999, p. 16) ${ }^{21}$.

Segundo o diagnóstico levantado pelos próprios indígenas serranos, as causas da violência e da destruição da natureza são localizadas justamente na incompreensão dos seus "irmãos de existência" civilizados sobre o sentido da comunicação e interligação essencial do homem com o mundo. Para eles, os irmãos mais novos não compreendem que essa "incomunicação" é a fonte dos desequilíbrios que afeta a existência harmônica de tudo quanto existe (yuluka), gerando consequências não só para eles que, como indígenas, veem prejudicada sua função como cuidadores dos conhecimentos e códigos consignados na Lei de Origem, mas para os não indígenas que habitam e constroem um mundo cada vez mais isolado da verdadeira essência de todas as coisas.

A postura crítica dos indígenas serranos é permanente. Diante da destruição permanente da vida em todas as suas manifestações, que atinge cada vez com mais força suas comunidades e autoridades e aos seus irmãos de existência (a água, as árvores, os rios, o petróleo, as

\footnotetext{
21 Tradução livre de: "Los tiempos no son los mismos de hace 500 años, cuando comenzó el contacto y la intromisión del hermanito menor en nuestro territorio y nuestro destino. Muchas cosas han cambiado, como por ejemplo, ya hemos perdido buena parte de los sitios sagrados fundamentales para la reproducción de la ley de Seynekun, que es la reproducción de la misma naturaleza y de la cultura. Esto no es un problema de unos cuantos indígenas caprichosos, es un problema que involucra a toda la humanidad. Por qué decidimos esto?. La Sierra Nevada es el corazón del mundo, aquí están los orígenes de todo cuanto existe, siguiendo la ley de Sé, espiritualmente nosotros continuamos revitalizando la vida, hacemos la práctica, hasta donde podemos, de comunicarnos con los Padres espirituales de todos y cada uno de los seres que conforman la vida. Lastimosamente muchos de los sitios necesarios para continuar nuestra misión se han perdido, o no tenemos acceso a ellos, o por la concepción de desarrollo (cada vez más equivocada) del hermanito menor se han deteriorado" (OGT, 1999, p. 16).
}

Espaço Ameríndio, Porto Alegre, v. 7, n. 1, p. 170-195, jan./jun. 2013. 
PATRÍCIA LORA LÉON - “Caminhar pelos próprios caminhos”...

pedras), consideram uma tarefa urgente o reestabelecimento dessa comunicação essencial que parece estar totalmente apagada na forma de pensar e de agir do civilizado. Para eles, segundo o Mamo arhuaco Avinteiru, nem a natureza nem a vida como um todo são considerados objetos de cuidado, e sim alvo de destruição ou de apropriação para o benefício de poucos, apagando a ligação que vincula o humano com a essência de todas as coisas, para no final das contas constituírem cada um dos elementos com os quais interagem na relação com o mundo como fins em si mesmos, objetos de um propósito que não entende a comunicação essencial como o princípio fundante da vida e do equilíbrio universal:

\begin{abstract}
A nossa reflexão desde as partes mais altas da Serra, todos os dias, o tempo todo, é para que a humanidade retorne à busca do seu verdadeiro equilíbrio. Parece um pouco difícil, mas com esforço conseguiremos. Sabemos de irmãos mais novos com sentimentos bons, com boas ideias, mas o que vemos errado é que, de repente, as bases [do pensamento] de vocês não estão bem alicerçadas. [vocês] Tem sido estratificados demais pelas carreiras, pelas profissões, para afastálos, para desuni-los e, assim, cada um especializa-se no seu campo e não faz isso pelo seu irmão senão para sair avante no que cada um sabe; isso nos desequilibra. Não só o pensamento; desequilibra-se a ideia que nós temos em função do que representam as grandes riquezas que a terra possui (UNIVERSO ARHUACO, 1997, p. 15) ${ }^{22}$.
\end{abstract}

Daí a insistência dos povos Kogi, Wiwa, Arhuaco e Kankuamo em caminhar pelos próprios caminhos que os levam à continuidade da comunicação essencial em e com o mundo e à busca de alternativas que Ihes permitam o reestabelecimento dessa comunicação no meio dos desequilíbrios e bloqueios que advêm desta incomunicação. Surge daí a

\footnotetext{
${ }^{22}$ Tradução libre de: "A diario y en todo momento, nuestra reflexión desde lo más alto de la Sierra es porque la humanidad vuelva a buscar su verdadero equilibrio. Parece un poco difícil esto, pero si hacemos un esfuerzo lo podemos lograr. Sabemos que hay hermanos menores con buenos sentimientos, con buenas ideas, pero lo único malo que vemos es que de pronto las bases de ustedes no las han podido cimentar muy bien. Los han estratificado mucho con las carreras, las profesiones, para alejarlos, para desunirlos y así, cada uno se especializa en su campo, y no lo hace por su hermano, sino sólo para salir avante en lo que sabe y eso es irse desequilibrando. No solamente el pensamiento, se va a desequilibrar la idea que nosotros tenemos en función de lo que representan las grandes riquezas que posee la tierra" (UNIVERSO ARHUACO, 1997, p. 15).
}

Espaço Ameríndio, Porto Alegre, v. 7, n. 1, p. 170-195, jan./jun. 2013. 
PATRÍCIA LORA LÉON - “Caminhar pelos próprios caminhos”...

importância capital de criar vasos comunicantes capazes de operar "de duas maneiras" essa comunicação, isto é, transformando tanto os conteúdos e os termos da relação dos indígenas serranos com a sociedade nacional, como os princípios e as formas de relação do homem com a diversidade espiritual e material constitutiva da realidade compartilhada do mundo.

Nesse contexto, a constituição de expressões organizativas indígenas coerentes com os princípios da Lei de Origem, a criação de documentos políticos que incorporam as categorias do pensamento próprio e os posicionamentos conjuntos frente aos problemas que afetam sua existência enquanto povos, a elaboração de peças comunicativas realizadas na perspectiva própria e pelos integrantes das comunidades indígenas serranas, e a participação de lideranças espirituais e políticas em espaços acadêmicos, das organizações sociais e governamentais ou de organismos internacionais, nos quais o pensamento próprio é apresentado e colocado no diálogo e em relação com outras perspectivas do mundo para além das fronteiras territoriais da Serra Nevada (outras cidades colombianas e em alguns casos na Europa e nos Estados Unidos), dizem respeito ao seu propósito político de estabelecer as pontes de comunicação necessárias para procurar a compreensão vital dos "outros" sobre o que é o sentido de sua existência como povos serranos, e assim sendo, persistir na sua responsabilidade no cuidado dos canais e formas de comunicação que possibilitam o restabelecimento da existência equilibrada do homem em e com o mundo.

Referencias bibliográficas

CTC - CONSEJO TERRITORIAL DE CABILDOS DE LA SIERRA NEVADA DE SANTA MARTA. Declaración conjunta de las cuatro organizaciones indigenas de la Sierra Nevada de Santa Marta para la interlocución con el Estado y la sociedad nacional. Valledupar, 1999. Santa Marta, 2003.

Lineamientos para la coordinación institucional (Documento de trabalho). Visión Ancestral Indígena para el Ordenamiento Territorial de la Sierra 
PATRÍCIA LORA LÉON - “Caminhar pelos próprios caminhos”...

Nevada de Santa Marta. (Documento de trabalho). Santa Marta, 2006.

Posición de los cuatro pueblos indígenas de la Sierra Nevada de Santa Marta frente a los proyectos multipropósito de Puerto Brisa en Dibulla y represas en Besotes y Rancheria: afectación a nuestras culturas. (Documento de trabalho). Santa Marta, 2007.

Declaración conjunta de las organizaciones indígenas de la Sierra Nevada para la interlocución con el Estado y la Sociedad Nacional. Santa Marta: Imagen Visual, 2009.

FAJARDO, Luis Alfonso, GAMBOA, Juan Carlos. Multiculturalismo y derechos humanos: una perspectiva desde el pueblo indígena wiwa de la Sierra Nevada de Santa Marta. Bogotá: ESAP, 1998.

OGT - ORGANIZACIÓN GONAWINDUA TAYRONA. Documento Difusión y consulta del ordenamiento territorial. (Documento de trabalho). Santa Marta, 1993.

.Lineamientos de los pueblos indígenas de la Sierra Nevada para el manejo ambiental. (Documento de Trabalho). Santa Marta, 1999.

PUMAREJO, Adriana; MORALES, Patrick. La recuperación de la memoria histórica de los kankuamo: un llamado de los antiguos - Siglos XX-XVIII. Bogotá: Universidad Nacional de Colombia, 2003.

REICHEL-DOLMATOFF, Gerardo. Notas sobre el simbolismo religioso de los indios de la Sierra Nevada. Bogotá: Universidad de los Andes, 1966.

Templos kogi: Introducción al simbolismo y a la astronomía del espacio sagrado. Revista colombiana de antropología, Bogotá, v. 19, n. 4, p. 199-245, 1975.

Los Kogi, una tribu de la Sierra Nevada de Santa Marta, Colombia. Tomo II. Bogotá: Procultura, 1985.

RUBIO SERRANO, Rocio. Gonawindua Tayrona una organización indígena de la Sierra Nevada de Santa Marta. Trabalho de conclusão de Grado (Graduação Antropologia) Universidad de Los Andes Bogotá (Colômbia), 1997.

SERJE, Margarita. La invención de la Sierra Nevada. Revista Antípoda, Bogotá, v. 7, p. 197-229, 2008.

ULLOA, Astrid. La construcción del nativo ecológico. Bogotá: Instituto Colombiano de Antropologia e Historia/Colciencias, 2004.

UNIVERSO ARHUACO. Compilação de documentos indígenas apresentados no VII Festival de Poesia de Medellín. Medellín: Editorial Copiyepes, 1997.

Espaço Ameríndio, Porto Alegre, v. 7, n. 1, p. 170-195, jan./jun. 2013. 